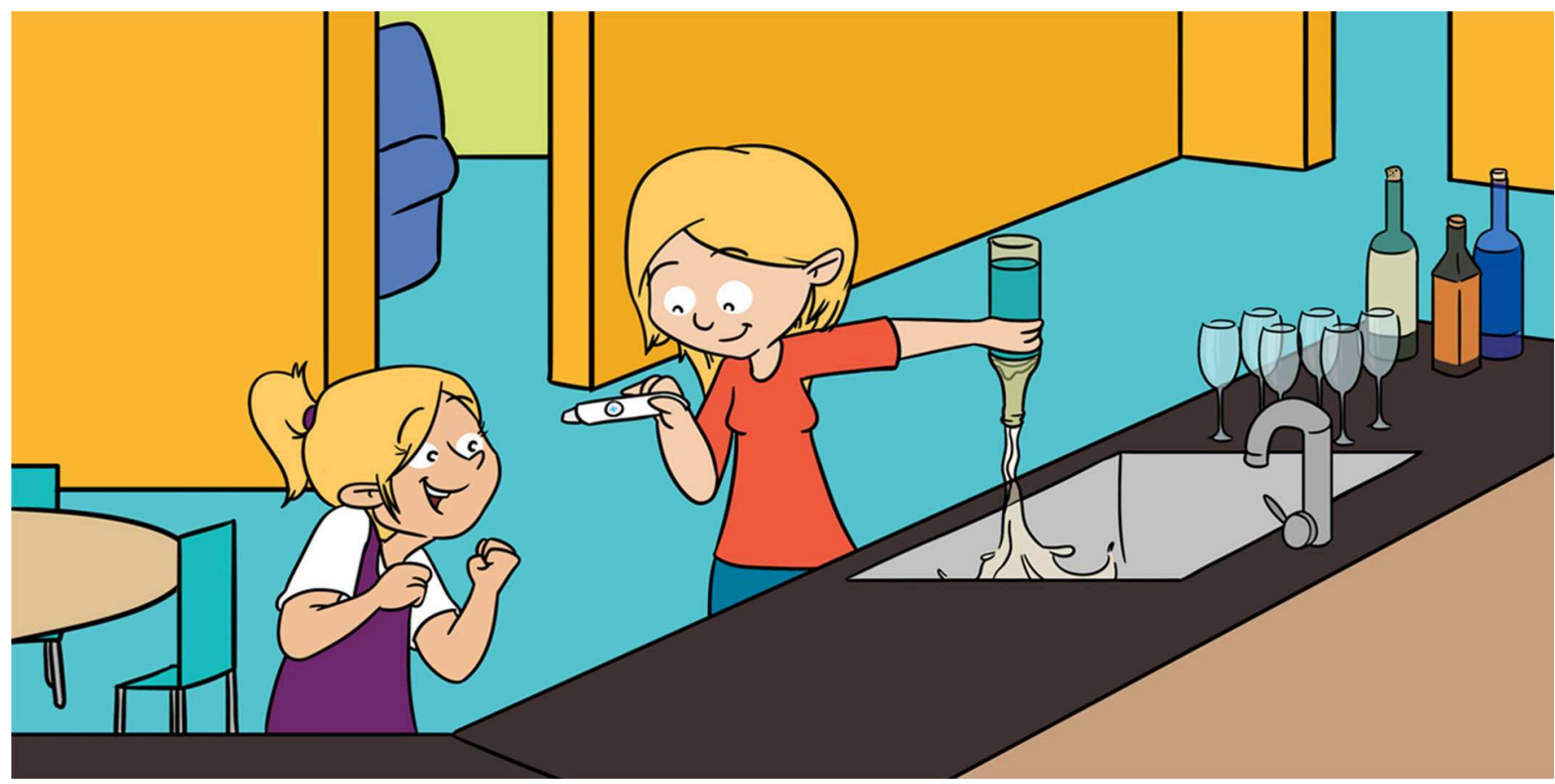

\title{
WHY ALCOHOL CAN HURT BABIES BEFORE THEY ARE BORN
}

Nathaniel G. Pavlik ${ }^{1}$, Jessie Newville ${ }^{2}$ and Jessie R. Maxwell ${ }^{1,2^{*}}$

${ }^{1}$ Department of Pediatrics, University of New Mexico School of Medicine, Albuquerque, NM, United States

${ }^{2}$ Department of Neurosciences, University of New Mexico School of Medicine, Albuquerque, NM, United States

YOUNG REVIEWER:

RAHI

AGE: 12
Some chemicals can be really harmful to the body. This is especially true for babies before they are born, because many important parts of their bodies are still forming. Alcohol is a chemical found in some adult drinks that is harmful for babies. If a mother drinks alcohol when she is pregnant, the baby growing inside of her will also be exposed to the alcohol. This situation is called prenatal alcohol exposure. If a baby is exposed to alcohol before it is born, the alcohol can damage cells in the developing brain and prevent the brain's proper functioning. This can make it hard to go to school, to learn, and to play. Right now, scientists and doctors are working to figure out how to help these babies heal and how to let people know that alcohol can hurt developing babies.

\section{WHAT IS PRENATAL ALCOHOL EXPOSURE?}

Prenatal alcohol exposure (PAE) is the name doctors use to describe when a baby is exposed to alcohol before it is born. Before a baby is 


\section{NEURON}

A type of cell in the brain that helps communicate what is happening in the body.

\section{GLIAL CELLS}

A type of cell in the brain that helps neurons by sending messages faster, by getting rid of extra neurons that are not needed, and by helping neurons grow in the right place of the brain at the right time.

\section{RADIAL GLIAL CELLS}

A type of glial cell that helps new neurons travel to the places they need to be. born, it gets the food it needs to grow from the food its mother eats. When the mother eats a meal, the food is digested into nutrients that are sent throughout her body and to the baby. Unfortunately, if the mother drinks alcohol, the alcohol will be digested and sent to the baby as well. This is bad, because alcohol can hurt cells, which are what our bodies are made of. If too many of the cells in the baby's body are hurt, then parts of its body, such as the brain, would not grow properly.

The brain is the organ that is hurt the most by PAE [1]. The brain is an important and complex organ that is made up of many different types of cells. These cells work together to help the brain control the rest of the body. The brain controls the body by sending messages to other body parts. These messages tell the body what to do. If the cells in the brain are damaged by alcohol, the brain might not be able to work properly. In the United States, about forty percent of all women drink alcohol during pregnancy [1]. This means that PAE affects a lot of babies and is a really big problem. This article will explain what happens to the cells in a baby's brain when that baby is exposed to alcohol before it is born.

\section{CELLS IN THE BRAIN}

There are many different types of cells in the brain. Some, called neurons, send chemical and electrical messages to each other to communicate what is happening in the body. Neurons are very important and allow you to think and feel. Your brain is not only made up of neurons, though. Neurons are helped by a special set of cells called glial cells. Glial cells help neurons stay healthy by doing three important jobs: they help neurons send messages faster; they help get rid of extra neurons that are not needed; and they make sure neurons grow in the right place at the right time. Different types of glial cells accomplish these jobs and all types of glial cells can be affected by PAE.

\section{RADIAL GLIAL CELLS}

Radial glial cells are a type of glial cell found in a developing baby's brain. The job of radial glial cells is to help new neurons travel to the places they need to be. Some radial glial cells change and become other types of glial cells, and we will talk about the other types later. If radial glial cells do not change into a different type of cell, they help neurons move to the right place in the brain. Radial glial cells in the center of the brain grow long, thin structures toward the outside of the brain. Neurons can use these structures like ropes, to pull themselves to where they need to be [2].

There are three major ways alcohol can damage the radial glial cells in a baby's brain. Alcohol causes radial glial cells to create fewer long, thin structures that help neurons move. Alcohol also makes radial glial cells 
Figure 1

The "Normal" frame shows the radial glial cell (blue) extending itself toward the surface of the brain, and a migrating cell (purple) using the radial glial cell to pull itself to its proper location. The second frame explains the effect of PAE, which results in fewer radial glial cells.

\section{Figure 2}

In the "Normal" frame, the microglia (green) are getting rid of unnecessary neurons (blue). In the frame titled "Prenatal Alcohol Exposure," the microglia have gotten rid of useful neurons as well as unnecessary neurons.

\section{MICROGLIA}

A type of cell in the brain that helps to get rid of anything in the brain that can make the brain cells sick.

\section{ASTROCYTE}

A type of glial cell in the brain that connects to multiple neurons and helps tell neurons when to grow and move.
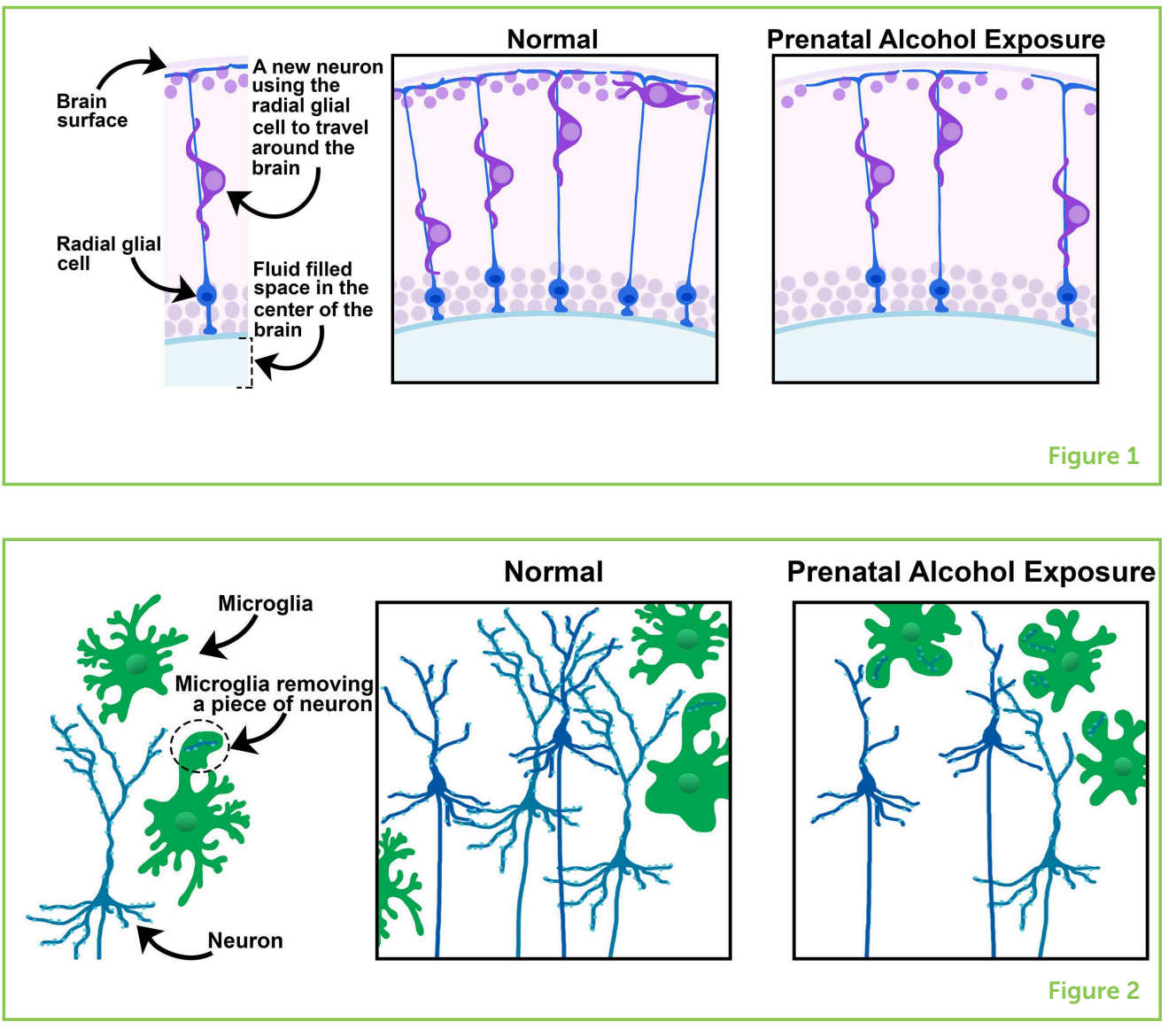

less likely to turn into other important types of cells. Lastly, alcohol can hurt radial glial cells so much that many of them die. The damage to radial glial cells is also one of the reasons why parts of a baby's brain may not form correctly (Figure 1). This kind of injury may make learning very difficult and even cause some health problems for babies exposed to alcohol before they are born [2].

\section{MICROGLIA}

Another type of glial cell is called the microglia. Microglia are very common and make up $10 \%$ of all the cells in the brain. The job of microglia is to get rid of anything in the brain that can make the brain cells sick. Their other job is to get rid of cells that are not healthy or useful. Normally, microglia only get rid of dangerous or useless cells. But when they are exposed to alcohol, they start getting rid of healthy cells too, which can hurt the brain (Figure 2) [2].

\section{ASTROCYTES}

A third type of glial cell is called the astrocyte. Each astrocyte connects to multiple neurons. Astrocytes help neurons stay healthy and tell them when to grow and move. PAE stops astrocytes from communicating 
Figure 3

Under normal

conditions,

multiple astrocytes

(yellow) are connected

to both blood vessels

(red) and neurons

(blue), providing

neurons with important

messages and

nutrients. After PAE,

there are many fewer

astrocytes available to

take care of the

neurons.

\section{OLIGODENDROCYTE}

A type of cell in the brain that makes long arms that wrap around neurons, kind of like the rubber coating that covers the wires in your electronics. This wrapping is called the myelin sheath.

\section{MYELIN SHEATH}

A coating around neurons, made by oligodendrocytes, that helps them send messages.

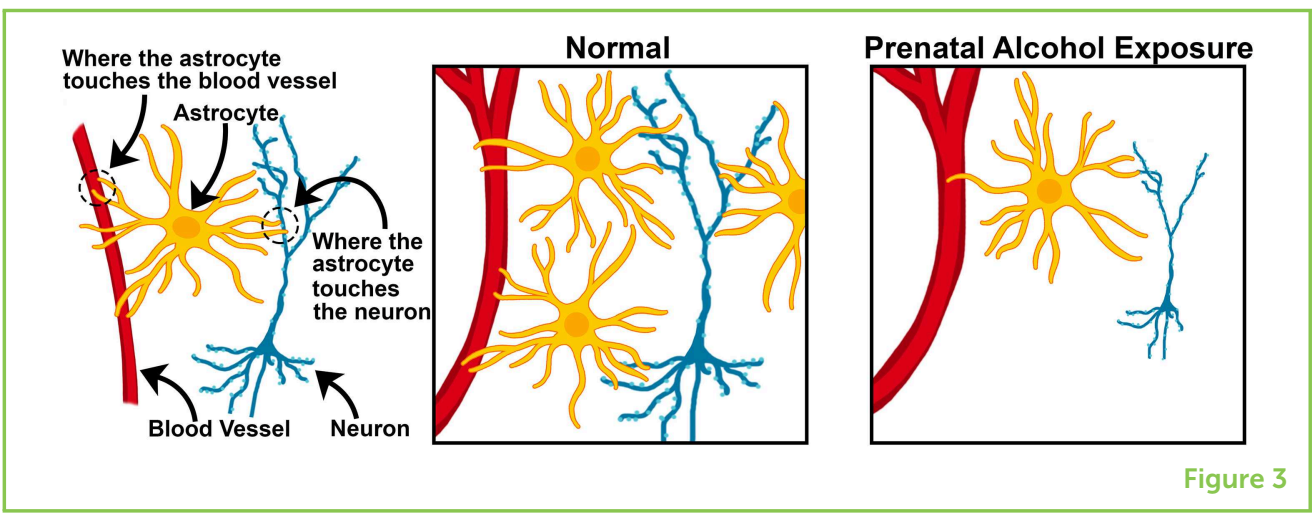

with neurons. Enough alcohol exposure can even destroy an astrocyte entirely. In short, PAE causes there to be fewer functional astrocytes as shown in Figure 3. This means that neurons would not have as much support and would not receive messages telling them when to grow and move [3]. Without these messages, many neurons would not move to the right parts of the brain or grow.

\section{OLIGODENDROCYTES}

The last type of glial cell we will discuss is called the oligodendrocyte. Oligodendrocytes make long arms that wrap around neurons, kind of like the rubber coating that covers the wires in your electronics. This wrapping is called the myelin sheath. The myelin sheath is important because it helps keep neurons healthy. Without it, neurons would not be able to send messages to one another or tell the various parts of the body what to do. If a baby is exposed to alcohol before it is born, the alcohol can damage the myelin sheaths and the oligodendrocytes that form them (Figure 4). With damaged myelin sheaths, communication between neurons does not happen as well. This poor communication between neurons can cause kids who were exposed to alcohol before they were born to have problems learning in school.

\section{HOW DO DOCTORS KNOW IF A BABY HAS BEEN EXPOSED TO ALCOHOL?}

Even though it can be hard to tell if a baby has been exposed to alcohol, doctors can sometimes diagnose severe alcohol exposure because the baby looks different. Doctors look at the space between the baby's eyelids to see if that space is narrower than a normal. They also look to see if the baby has a thin area between the upper lip and the skin above the lip and if the area between the upper lip and nose is smooth. Sometimes, the head of a baby suffering from extreme PAE is smaller than usual and may even weigh less or look shorter than usual. The more a mother drinks when she is pregnant, the more her baby is likely to have these physical characteristics [4]. 
Figure 4

Under normal conditions, the oligodendrocytes (pink) wrap part of themselves around neighboring neurons (blue) to help the neurons transmit their messages. After PAE, there are fewer oligodendrocytes to help the neurons transmit their messages.

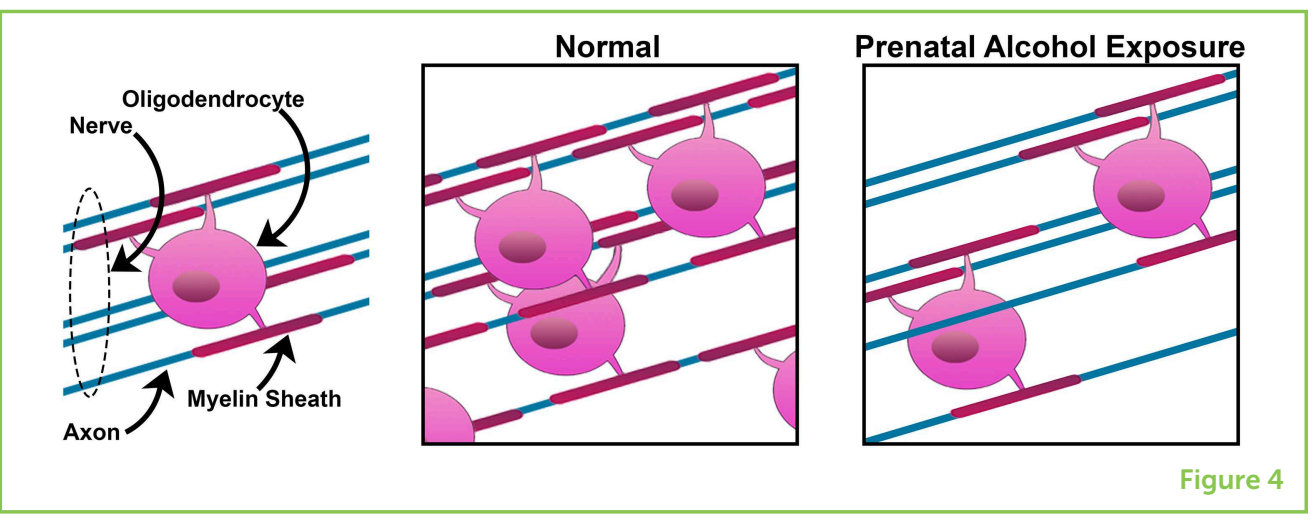

Drinking alcohol at different times during a pregnancy can have different effects on the baby. Babies grow inside their mothers for 37-40 weeks and are most likely to have the characteristics mentioned above if the mothers drink during weeks 6-12 of the pregnancy. However, some of those characteristics can be caused by alcohol consumption at other points in development as well [4].

\section{CONCLUSION}

Prenatal alcohol exposure causes serious and permanent damage to babies before they are born. Alcohol hurts the baby by damaging cells that help form important organs. Many organs can be affected, such as the intestines, kidneys, and heart, but the organ most affected is the brain. Alcohol can damage or destroy the glial cells that help neurons stay healthy and functional. Doctors and scientists are working to find ways to help babies with PAE, because right now there is not a treatment available. PAE can be difficult to diagnose, but doctors can recognize affected babies because they often have facial features that are unique to people who have had PAE. These features most often result from alcohol exposure during weeks 6-12 of pregnancy, but some of the features can be caused by alcohol exposure at other stages in development. It is important to remember that alcohol affects other organs as well as the brain and can be harmful at any stage of a pregnancy.

\section{REFERENCES}

1. Caputo, C., Wood, E., and Jabbour, L. 2016. Impact of fetal alcohol exposure on body systems: a systematic review. Birth Defects Res. C Embryo Today 108:174-80. doi: 10.1002/bdrc.21129

2. Wilhelm, C. J., and Guizzetti, M. 2016. Fetal alcohol spectrum disorders: an overview from the glia perspective. Front. Integr. Neurosci. 9:65. doi: 10.3389/fnint.2015.00065

3. Guizzetti, M., Zhang, X., Goeke, C., and Gavin, D. P. 2015. Corrigendum: "Glia and Neurodevelopment: Focus on Fetal Alcohol Spectrum Disorders". Front. Pediatr. 3:27. doi: 10.3389/fped.2015.00027 
4. Feldman, H. S., Jones, K. L., Lindsay, S., Slymen, D., Klonoff-Cohen, H., Kao, K., et al. 2012. Prenatal alcohol exposure patterns and alcohol-related birth defects and growth deficiencies: a prospective study. Alcohol. Clin. Exp. Res. 36:670-6. doi: 10.1111/j.1530-0277.2011.01664.x

SUBMITTED: 11 June 2019; ACCEPTED: 13 November 2019;

PUBLISHED ONLINE: 29 November 2019.

EDITED BY: Bergithe Eikeland Oftedal, University of Bergen, Norway

CITATION: Pavlik NG, Newville J and Maxwell JR (2019) Why Alcohol Can Hurt Babies Before They Are Born. Front. Young Minds 7:132. doi: 10.3389/frym.2019. 00132

CONFLICT OF INTEREST: The authors declare that the research was conducted in the absence of any commercial or financial relationships that could be construed as a potential conflict of interest.

COPYRIGHT @ 2019 Pavlik, Newville and Maxwell. This is an open-access article distributed under the terms of the Creative Commons Attribution License (CC BY). The use, distribution or reproduction in other forums is permitted, provided the original author(s) and the copyright owner(s) are credited and that the original publication in this journal is cited, in accordance with accepted academic practice. No use, distribution or reproduction is permitted which does not comply with these terms.

\section{YOUNG REVIEWER}
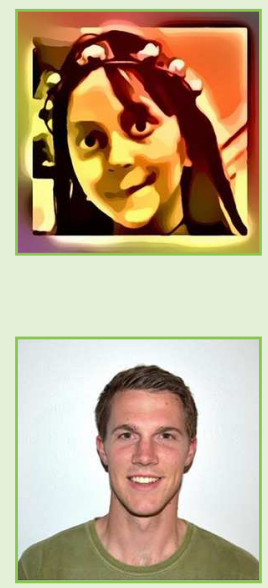

RAHI, AGE: 12

I am a 12 years old girl who want to know about interesting topics in science and love dancing and play with my dog Ringo.

\section{AUTHORS}

\section{NATHANIEL G. PAVLIK}

Nathaniel Pavlik is a research technician in the Department of Pediatrics at the University of New Mexico Health Science Center. He is currently assisting Dr. Jessie R. Maxwell in her research regarding prenatal opioid and alcohol exposure. The goal of the research is to improve the treatment of affected infants. Nathaniel enjoys spending his time outside of the laboratory reading and rock climbing.

\section{JESSIE NEWVILLE}

Jessie Newville is a researcher in the Neurosciences Department at the University of New Mexico. She loves learning about all of the different cell types in the brain. Her current research investigates how these different cell types are affected when babies have brain injury. Through her research, she hopes to contribute to the larger effort in developing medicine that helps babies who experience brain injury get better. When she has free time, she explores New Mexico, gardens, and appreciates poetry. 


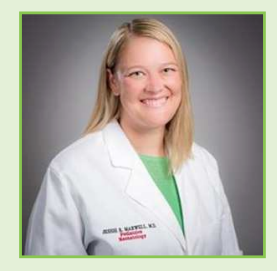

\section{JESSIE R. MAXWELL}

Dr. Maxwell is a neonatologist and a clinician scientist who is dedicated to improving the long-term outcomes of infants born preterm or ill. She realized how many infants with prenatal alcohol exposure are born with other problems. These newborns are at high risk of neurodevelopment delays and, as a clinician, the support she can offer is limited. However, in the laboratory she is able to work toward expanding the current information known about these infants, with the ultimate goal of finding ways to help them.*Jrmaxwell@salud.unm.edu 